\title{
Negative Cross Resistance of Leucinodes orbonalis Population of Brinjal to Newer Molecule Spinetoram 12 SC W/V (11.7 W/W)
}

\author{
M. Visnupriya" and N. Muthukrishnan \\ Department of Agricultural Entomology, Tamil Nadu Agricultural University, \\ Coimbatore-3, Tamil Nadu, India \\ *Corresponding author
}

\section{A B S T R A C T}

\begin{tabular}{|l|}
\hline K e y w o r d s \\
$\begin{array}{l}\text { Spinetoram } 12 \text { SC, } \\
\text { Brinjal, Negative cross } \\
\text { resistance, Leucinodes } \\
\text { orbonalis, Probit } \\
\text { analysis. }\end{array}$ \\
\hline Article Info \\
\hline $\begin{array}{l}\text { Accepted: } \\
15 \text { October } 2017 \\
\text { Available Online: } \\
10 \text { December } 2017\end{array}$ \\
\hline
\end{tabular}

\section{Keywords}

\section{Introduction}

Eggplant or Brinjal, Solanum melongena L. is native to India and cultivated almost throughout the year in all parts of the world. It contributes to $9 \%$ of the total vegetable production of the country (Sidhu and Dutta, 2007). People relish brinjal as a table vegetable throughout India due to its nutritive value. It is grown in almost all states of India in an area of 5.10 lakh hectares with the production of 88.0 lakh tonnes of fruits, making country the second largest producer after China. Although India ranks second after China in global eggplant production, crop productivity is relatively low. This commercial crop is infested by more than 23 pests (Muthukrishnan et al., 2005) from the time of planting to harvest. According to Asian Vegetable Research and Development Centre (Anon., 2009) the key pests responsible for deterioration of quality and quantity in brinjal is shoot and fruit borer, Leucinodes orbonalis (Guenee), aphid (Aphis gossypii Glover), jassid (Amrasca biguttula biguttula Ishida), epilachna beetle, Henosepilachna vigintioctopunctata Fabricius and white fly (Bemisia tabaci Gennadius).

Shoot and fruit borer, L. orbonalis Guenee (Lepidoptera: Pyralidae) is the key pest among these pests throughout Asia (Ghosh et al., 2003). In India, this pest has a countrywide distribution and has been 
categorized as the most destructive and serious pest causing huge losses in brinjal (Patil, 1990). Larvae bore into the young shoots and feed on internal tissues resulting in wilting of the shoot, which reduces plant growth and number and size of fruits (Atwal and Dhaliwal, 2007). Fruit infestation ranged from 31 to $90 \%$ in Bangladesh (Rahman, 1997), 37-63\% in different states in India (Dhankar, 1988) and 50-70\% in Pakistan (Saeed and Khan, 1997). The pest has been reported to inflict losses to the tune of $20.7-$ $60.0 \%$ in Tamil Nadu (Raja et al., 1999), $70 \%$ in Andhra Pradesh (Sasikala et al., 1999), $80 \%$ in Gujarat (Jhala et al., 2007) and 41\% in Himachal Pradesh (Lal et al., 1976).

Insecticides have been used extensively for the control of these insect-pests for quicker remedy. Available reports reveal that repeated applications of synthetic chemical insecticides dominate the other means for the control of the pest and their indiscriminate use has led to the resurgence of whitefly, aphid and mite (Rahman, 1997). The insecticides used mostly are organophosphates, carbamates and synthetic pyrethroids. However, insecticides such as quinalphos, monocrotophos, carbaryl, carbofuran and fenvalerate have been reported to fail in controlling the shoot and fruit borer effectively which consequently increased cost of production (Radhika et al., 1997).

Muggleton (1984) used the term "resistant" (i) to describe a resistant population which contains a single individual capable of surviving a laboratory dose of insecticide which would kill almost all (at least 99.9\%) of a laboratory strain and (ii) to describe only a field population which could not be controlled by field dose properly applied. For resistance management, it is important that resistance is detected at the earlier stage. For effective implementation of resistant management practices, it is essential to have some estimate of changes of resistant level throughout the area when a particular chemical is applied (Taylor, 1983). These estimates rely on initial baseline levels of susceptibility and variability in population so that future comparisons can be made (Georghiou and Mellon, 1983). Spinetoram is effective against insect pest, $P$. xylostella which is resistant to the existing insecticides (organophosphates, chitin biosynthesis inhibitor and synthetic pyrethroids) in crop protection (Anonymous, 2012). However, there are no reports on negative cross resistance of shoot and fruit borer, Leucinodes orbonalis. Therefore, this study was undertaken with the objective to investigate the negative cross resistance Leucinodes orbonalis population of brinjal to spinetoram $12 \mathrm{SC}$ in the laboratory.

\section{Materials and Methods}

\section{Mass culturing of brinjal shoot and fruit borer, Leucinodes orbonalis}

Mass culturing of brinjal shoot and fruit borer (BSFB) was done as per the procedures described by Selvi (2010). BSFB damaged fruits harbouring larvae were collected from the farmers' field. The fruits were placed in plastic trays containing dry river sand in a culture room at $26 \pm 1^{\circ} \mathrm{C}, \mathrm{RH} 75 \pm 5 \%$ and photoperiod 16:8 $\mathrm{h}$ scoto/photo regime. The fully grown larvae came out of the fruits were allowed to pupate in dry river sand.

The pupae were collected and placed in a plastic jar covered with muslin cloth for adult emergence. Subsequently, adults were sexed and confined at 20 pairs per oviposition cage with tender brinjal twigs/muslin cloth as oviposition substrate. Cotton swabs dipped in honey solution (10\% sugar and $0.1 \%$ multivitamin drops) were provided as adult feed. Flat creamy, yellow, scaly eggs were laid on the leaf surface/muslin cloth. Eggs laid on twigs/muslin cloths were placed in plastic containers lined with muslin cloth for larval emergence. 
After 3-4 days the newly hatched neonate larvae were transferred to potato. Medium sized young potatoes were washed well in water and a suspension containing $500 \mathrm{mg} / \mathrm{lr}$ of carbendazim and $40 \mathrm{mg} / \mathrm{lr}$ streptomycin sulphate. The tubers were slightly peeled in three to four places and neonate larvae at the rate of 30-40 larvae / tuber were placed over the peeled region. The tubers were placed over dry river sand individually, inside a plastic container covered with muslin cloth. The matured larvae came out of potato and pupated in dry sand medium. Subsequent to pupation, adult emergence and oviposition were followed as described earlier for field collected brinjal fruits. Newly hatched first instar larvae were transferred to peeled regions of potato tubers and reared for many generations in the laboratory conditions for further laboratory experiments.

\section{Negative cross resistance of $L$. orbonalis population of brinjal to spinetoram $12 \mathrm{SC}$}

Brinjal farmers often use several insecticides of varied chemical nature and mode of action. This situation leads to the development of resistance to the borer pest $L$. orbonalis. There is also a hypothesis that new chemistry molecules are desired not to show any cross resistance with the existing insecticides used against crop pests. In order to test verify the hypothesis, conventional insecticides resistant field populations of $L$. orbonalis from brinjal were collected and assessed for their susceptibility to various concentrations of spinetoram $12 \mathrm{SC}$.

L. orbonalis larvae reared in the laboratory for five generations without any exposure to conventional insecticides were used as standard reference. Field population of $L$. orbonalis larvae were collected from farmer's holding (Mr. Balamurugan) at Thaniyamangalam, Melur Block, Madurai District, which might had been in selection pressure due to the continuous application of insecticides like insect growth regulators, organophosphates (profenophos and quinalphos), pyrethroids (cypermethrin) and carbamates (carbaryl). These field collected $L$. orbonalis populations were reared in the Insectary of Agricultural College and Research Institute, Madurai separately.

Experiment on acute toxicity of spinetoram 12 SC against $L$. orbonalis was done by fruit dip technique (Ahmad et al., 2003). Spinetoram $12 \mathrm{SC}$ was diluted with water to obtain six different concentrations $(1.2 \mathrm{ppm}$, $2.4 \mathrm{ppm}, 3.6 \mathrm{ppm}, 4.8 \mathrm{ppm}, 6.0 \mathrm{ppm}$ and 7.2 ppm). Tender small sized brinjal fruits obtained from potted plants were dipped for 60 seconds in different concentrations of spinetoram 12 SC and left dry under laboratory condition for one hour. Fruits of untreated control were dipped in water. All the treated fruits were placed in large plastic containers separately and covered with muslin cloth. Laboratory reared L. orbonalis larvae (20) were released on treated fruits. Similarly, 20 numbers of field collected $L$. orbonalis larvae were also placed on another set of treated fruits. All the two experiments were replicated three times. The larvae were considered dead if they became desiccated with shortened body and dark cuticle, and/or unable to move in a coordinated manner when disturbed with a needle. In this acute toxicity experiment, observations on larval mortality were fixed till 72 hours of exposure as spinetoram 12 SC tested was lepidoptericide characterized by stomach action showing slower mortality (Ahmad et al., 2003). The cumulative mortality data were observed till $72 \mathrm{~h}$ at $24 \mathrm{~h}$ interval and corrected by Abbott's formula.

\section{Statistical analysis}

The statistical analysis of the data on mortality was subjected to the Abbott formula 
(Abbott, 1925) for correction wherever required. Probit analysis was used to calculate $\mathrm{LC}_{50}$ and $\mathrm{LC}_{95}$ values (Finney, 1971) through software computer programme.

\section{Results and Discussion}

Due to frequent application of insecticides on vegetables like brinjal most of the lepidopteron pests may have developed resistance. In general, newly developed compounds are desired not to show cross resistance with existing insecticides. With this background, field population of L. orbonalis from brinjal which was known to be tolerant to most of the conventional insecticides were collected and subjected to the in vivo toxicity of spinetoram $12 \mathrm{SC}$ to assess whether cross resistance exists.

Probit analysis criteria of field and laboratory strain of all $L$. orbonalis instars are presented in Table 1. Untreated larvae of both field and laboratory strains showed no mortality during the 48 hours of feeding. After 48 hours of feeding on spinetoram 12 SC-treated fruits, $\mathrm{LC}_{50} \mathrm{~S}$ of field larvae were $0.097,0.45,3.13$ and $6.58 \mathrm{ppm}$ for the $2^{\text {nd }}, 3^{\text {rd }}, 4^{\text {th }}$ and $5^{\text {th }}$ instars of $L$. orbonalis respectively. However, in the laboratory strain these values were $0.76,1.92,17.37$ and $49.55 \mathrm{ppm}$ for $2^{\text {nd }}, 3^{\text {rd }}$, $4^{\text {th }}$ and $5^{\text {th }}$ instars of $L$. orbonalis respectively. The results confirmed the greater $\mathrm{LC}_{50}$ of the laboratory strain than of the field strain. The laboratory strain of the $2^{\text {nd }}$ instar showed higher $\mathrm{LC}_{50}$ than $2^{\text {nd }}$ and $3^{\text {rd }}$ instars of field strain. Resistance ratio was $0.13,0.23,0.18$ and 0.13 for the $2^{\text {nd }}$ instar up to the $5^{\text {th }}$ instar of L. orbonalis (Table 2). These results corroborate with the findings of Arora (2002) who concluded that spinosad selected strain of Plutella xylostella (L.) did not show any cross resistance to certain conventional insecticides. Since toxicity of many insecticides decline as larvae age (Mayuravalli et al., 1985; Rao and Dhingra, 1996), insecticides should be applied against early larva stages to maximize control efficacy. Variable degrees of cross resistance in a variety of pest species between spinosad and other few insecticides have been reported (Dunley et al., 2006; Magna et al., 2007; Lambkin and Rice, 2007; Bielza, 2007; Sayyed et al., 2008b).

A study of cross resistance with spinosad in tobacco bud worm has been recently reported by Roe (2010). The estimated decrease in resistance was 11.36, 11.11, 16.67 and 9.61 for imidacloprid, spinosad, emamectin benzoate and profenofos, respectively and suggested that spinosad could be included in the control program of $S$. litura, due to its lower stability and higher reversion rate with insecticides bearing novel modes of action (Adeel et al., 2011).

Table.1 Probit analysis of larval instars of field L. orbonalis versus laboratory strain

\begin{tabular}{|c|c|c|c|c|c|}
\hline Larval instars & $\mathrm{LC}_{50}(\mathrm{ppm})$ & Lower limit & Upper limit & Folds & $\mathrm{LC}_{95}(\mathrm{ppm})$ \\
\hline Field $2^{\text {nd }}$ instar & 0.097 & 0.085 & 0.11 & 1.00 & 1.26 \\
\hline Field $3^{\text {rd }}$ instar & 0.45 & 0.32 & 0.67 & 4.64 & 2.14 \\
\hline Field $4^{\text {th }}$ instar & 3.13 & 2.11 & 4.09 & 32.24 & 44.82 \\
\hline Field $5^{\text {th }}$ instar & 6.58 & 5.42 & 7.59 & 67.77 & 89.75 \\
\hline Laboratory $2^{\text {nd }}$ instar & 0.76 & 0.51 & 1.02 & 7.82 & 3.36 \\
\hline Laboratory $3^{\text {rd }}$ instar & 1.92 & 1.53 & 2.40 & 19.78 & 7.21 \\
\hline Laboratory $4^{\text {th }}$ instar & 17.37 & 12.31 & 23.75 & 178.91 & 89.65 \\
\hline Laboratory $5^{\text {th }}$ instar & 49.55 & 40.26 & 62.71 & 510.37 & 167.99 \\
\hline
\end{tabular}


Table.2 Resistance ratio between field strain of L. orbonalis and laboratory strain

\begin{tabular}{|l|c|c|c|}
\hline Larval instars & $\mathbf{L C}_{\mathbf{5 0}}$ of field strain & $\mathbf{L C}_{\mathbf{5 0}}$ of laboratory strain & Resistance ratio \\
\hline $2^{\text {nd }}$ instar & 0.097 & 0.76 & 0.13 \\
\hline $3^{\text {rd }}$ instar & 0.45 & 1.92 & 0.23 \\
\hline $4^{\text {th }}$ instar & 3.13 & 17.37 & 0.18 \\
\hline $5^{\text {th }}$ instar & 6.58 & 49.55 & 0.13 \\
\hline
\end{tabular}

Spinetoram is effective against insect pests (P. xylostella and Adoxophyes honmai Yasuda) which are resistant to the existing insecticides (organophosphates, chitin biosynthesis inhibitor and synthetic pyrethroids) in crop protection (Anonymous, 2012).

During the 20th century, pesticide use has become integral for current agricultural practices, as has the challenge linked with pesticide resistance. Traditional resistance management plans have often used a "use and discard" approach, changing the chemical to target a different mode of action in the pest species once resistance becomes a problem in the field.

An alternative strategy is to identify compounds that confer negative crossresistance (NCR), where the NCR compound is more toxic to pesticide resistant insects as compared to their pesticide susceptible counterparts. Such an insecticide spinetoram 12 SC shows results for laboratory strains of $2^{\text {nd }}$ to $5^{\text {th }}$ instar of $L$. orbonalis registered higher $\mathrm{LC}_{50} \mathrm{~s}$ from 0.76 to $49.55 \mathrm{ppm}$. Thus field collected larvae of $L$. orbonalis from brinjal showed higher sensitivity towards spinetoram $12 \mathrm{SC}$.

\section{Acknowledgement}

The authors are grateful to M/S. Dow Agro Science India Pvt. Ltd, Mumbai for providing financial help during the course of investigation. Authors are also thankful to Tamil Nadu Agricultural University,
Coimbatore and Agricultural College and Research Institute, Madurai for granting permission to publish the results.

\section{References}

Abbott, W. S., 1925. A method of computing the effectiveness of an insecticide. J. Econ. Entomol., 18: 265-267.

Adeel, R., M. A. Saleem and Freed, S. 2011. Baseline susceptibility and stability of insecticide resistance of Spodoptera litura (F.) (Lepidoptera; Noctuidae) in the absence of selection pressure. Pakistan J. Zool. 43(5): 973-978.

Ahmad, M., M. I. Arif and Ahmad, Z. 2003. Susceptibility of Helicoverpa armigera (Lepidoptera: Noctuidae) to new chemistries in Pakistan. Crop Prot., 22: 539-544.

Anonymous. 2009. Indian horticulture database NHB. Ministry of Agriculture, Govt. of India, 154-61.

Anonymous. 2012. All India Coordinated Cotton Improvement Project, Annual Report, 2011-12.

Arora, R. K. 2002. Baseline susceptibility and quantification of resistance in Plutella xylostella (L.) to spinosad. http://whalonlab.msu.edu/rpmnews/ vol12_no.2/globe/rpm_g_arora.

Atwal, A. S. and Dhaliwal, G. S. 2007. Agricultural Pests of South Asia and their management, $5^{\text {th }}$ edn. Kalyani Publishers, India.

Bielza, P. 2007. Resistance to spinosad in the western flower thrips, Frankliniella occidentalis (Pergande) in greenhouses 
of south-eastern Spain. Pest Manag. Sci. 63: 682-687.

Dhankar, D. S. 1988. Progress in resistance studies in eggplant (Solanum melongena L.) against shoot and fruit borer of brinjal (Leucinodes orbonalis Guen.) infestation. Trop. Pest Manage., 34: 343-345.

Dunley, J. E., J. F. Brunner, M. D. Doerr and Beers, E. H. 2006. Resistance and crossresistance in populations of the leafrollers, Choristoneura rosaceana and Pandemis pyrusana in Washington apples. J. Insect Sci. 6: 1-7.

Finney, D. T. 1971. Probit Analysis. Second Edition. Cambridge University Press, London.318p.

Georghiou, G. P. and Mellon, R. B. 1983. Pesticide resistance in time and space. In: Pest resistance to pesticides, (eds.) G.P. Georghiou and S. Saito, Plenum press, New York, pp. 1-46.

Ghosh, S. K., N. Laskar and Senapati, S. K. 2003. Estimation of loss in yield of brinjal due to pest complex under Terai region of West Bengal. Environment and Ecology, 21(4): 764-769.

Jhala, R. C., M. G. Pate, A. J. Chanda and Patel, Y. C. 2007. Testing IPM strategy for Leucinodes orbonalis in farmer's field. In: Proc. National Symposium on Frontiers of Entomological Research (Eds.: Subrahmanyam, B. and Ramamurthy, V. V). 5 - 7, November 2007, New Delhi. p. 256.

Lal, O. P., R. K. Sharma, T. S. Verma, P. M. Bhagchandani and Chandra, J. 1976. Resistance in brinjal to shoot and fruit borer, Leucinodes orbonalis Guen. (Lepidoptera: Pyralidae). Veg. Sci., 3: 111-115.

Lambkin, T. A. and Rice, S. J. 2007. Baseline responses of Alphitobius diaperinus (Coleoptera: Tenebrionidae) to spinosad and susceptibility of broiler populations in Eastern and Southern Australia. J.
Econ. Entomol. 100: 1423-1427.

Magana, C., P. Hernandez-Crespo, F. Ortego and Castanera, P. 2007. Resistance to malathion in field populations of Ceratitis capitata. J. Econ. Entomol. 100: 1836-1843.

Mayuravalli, V. V. L., K. C. Punnaiah, G. P. V, Reddy and Rao, V. R. S. 1985. Laboratory evaluation of the relative toxicity of deltamethrin, permethrin and monocrotophos to the larvae of Spodoptera litura (Fab.). Indian J. Agric. Sci., 55(10): 645 - 647.

Muggleton, J. 1984. The evaluation of insecticide resistance and its relevance to control strategy. In: Proc. British Crop Prot. Conf., Corydon, U.K., pp. 585- 592.

Muthukrishnan, N., N. Ganapathy, R. Nalini and Rajendran, R. 2005. Pest Management in Horticultural Crops, Hindustan Graphics, Madurai. p. 373.

Patil, P. D. 1990. Technique for mass rearing of the brinjal shoot and fruit borer, Leucinodes orbonalis Guen. J. Entomol. Res., 14: 164-172.

Radhika, S., K. D. Reddy and Subbarathnam, G. V. 1997. Management of brinjal shoot and fruit borer, Leucinodes orbonalis (Guen.) with insecticides. J. Res., 25(3): 16-14.

Rahman, A. K. M. Z. 1997. Screening of 28 brinjal lines for resistance/tolerance against the brinjal shoot and fruit borer. Annual Report. Entomology Division, Bangladesh Agricultural Research Institute, Joydebpur, Gazipur, Bangladesh.

Raja, J., B. Rajendran and Pappiah, C. M. 1999. Management of brinjal shoot and fruit borer (Leucinodes orbonalis Guen.). Veg Sci., 26: 167-169.

Rao, G. R. and Dhingra, S. 1996. Relative susceptibility of different instars of Spodoptera litura (Fabricius) to some synthetic pyrethroids. J. Entomol. Res., 20(2): 103-108. 
Roe, R. M. 2010. Mechanism of resistance to spinosyn in the tobacco budworm, Heliothis virescens. Pest Biochem. Physiol., 96: 8-13.

Saeed, M. Q. and Khan, I. A. 1997. Population abundance and chemical control of brinjal fruit borer, Leucinodes orbonalis Guen. (Lepidoptera: Pyralidae). Sarhad J. Agric., 13:399-402 Sasikala, J., P. A. Rao and Krishnayya, P. V. 1999. Comparative efficacy of ecofriendly methods involving egg parasitoid, Trichogramma japonicum, mechanical control and safe chemical against Leucinodes orbonalis Guenee infesting brinjal. J. Entomol. Res., 23: 369-372.

Sayyed, A. H., M. Ahmad and Saleem M. A. 2008. Cross-resistance and genetics of resistance to indoxacarb in Spodoptera litura (Lepidoptera: Noctuidae). J. Econ. Entomol, 101: 472-479.

Selvi, C. 2010. Engieering insecticide resistance in brinjal against shoot and fruit borer, Leucinodes orbonalis. Unpub. Ph. D. Thesis. Tamil Nadu Agric. Univ., Coimbatore, India. 238p.

Sidhu, A. S. and Dutta, A. S. 2007. Current status of brinjal research in India. In: International Conference on Indigenous Vegetables and Legumes. Prospects for Fighting Poverty, Hunger and Malnutrition SHS. Acta Horticulturae, 752: 243-248.

Taylor, C. E. 1983. Evolution of resistance to insecticides and role of mathematical models and computer simulations. In: Pest resistance to pesticides, (eds.) G.P. Georghiou and S. Saito, Plenum press, New York, pp. 163-173.

\section{How to cite this article:}

Visnupriya, M. and Muthukrishnan, N. 2017. Negative Cross Resistance of Leucinodes orbonalis Population of Brinjal to Newer Molecule Spinetoram 12 SC W/V (11.7 W/W). Int.J.Curr.Microbiol.App.Sci. 6(12): 1790-1796. doi: https://doi.org/10.20546/ijcmas.2017.612.202 